\title{
Effects of roughage source, amount, and particle size on behavior and gastrointestinal health of veal calves
}

\author{
L. E. Webb, ${ }^{\star 1}$ E. A. M. Bokkers, ${ }^{*}$ L. F. M. Heutinck, † B. Engel, $\ddagger$ W. G. Buist, $\ddagger$ T. B. Rodenburg,§ \\ N. Stockhofe-Zurwieden,\# and C. G. van Reenen† \\ *Animal Production Systems Group, Wageningen University, PO Box 338, 6700 AH, Wageningen, the Netherlands \\ †Livestock Research, Wageningen University and Research Centre, PO Box 65, 8200 AB Lelystad, the Netherlands \\ łBiometris, Wageningen University, PO Box 100, 6700 AC Wageningen, the Netherlands \\ $\S$ Animal Breeding and Genomics Centre, Wageningen University, PO Box 338, $6700 \mathrm{AH}$, Wageningen, the Netherlands \\ \#Central Veterinary Institute, Wageningen University and Research Centre, PO Box 65, 8200 AB, Lelystad, the Netherlands
}

\begin{abstract}
The European Union 1997 Directive, stipulating that veal calves should be fed a minimum of 50 to $250 \mathrm{~g}$ of fibrous feed from 8 to $20 \mathrm{wk}$ of age, is vague. A fibrous feed ration maximum of $250 \mathrm{~g}$ has been implicated in welfare issues, namely the occurrence of abnormal oral behaviors and poor gastrointestinal health. Past research suggests that this amount is insufficient to prevent the development of abnormal oral behaviors and enabling good rumen development. Different sources and particle sizes of roughage could lead to very different welfare outcomes. In a $3 \times 2 \times 2$ factorial design, 240 group-housed calves $(10 \pm 1 \mathrm{~d} ; 46.1 \pm 0.1$ $\mathrm{kg}$ ) were fed different roughage sources (straw, maize silage, or maize cob silage; the latter 2 were dried and provided no extra moisture compared with straw) in 2 amounts (250 or $500 \mathrm{~g}$ of dry matter per day), and 2 particle sizes (chopped or ground). Roughage was supplemented to milk replacer (MR) from 2 wk after arrival. In addition, 60 calves were fed 1 of 3 additional control treatments: MR only $(\mathrm{n}=20)$, MR plus an iron supplement $(\mathrm{n}=20)$, or MR plus ad libitum hay $(\mathrm{n}=20)$. Oral behaviors were recorded using instantaneous scan sampling at 2-min intervals for $2 \mathrm{~h}$ in 3 periods per day, at 12 and 22 wk of age. Calves were slaughtered at 24 wk of age and rumen and abomasal health parameters were recorded. Limited provision of straw resulted in behavior comparable with that from unlimited provision of hay, with reduced tongue playing and oral manipulation of the environment, as well as increased chewing compared with diets with no roughage supplement. Straw prevented ruminal hairballs, but impaired rumen development and increased abomasal damage. A higher ration of roughage increased chewing (12 wk), decreased oral manipulation of the trough (12
\end{abstract}

Received September 7, 2012.

Accepted July 3, 2013.

${ }^{1}$ Corresponding author: laura.webb@wur.nl and $22 \mathrm{wk})$ and the pen (22 wk), and increased rumen weight. However, more roughage led to increased abomasal damage for certain parameters. Longer feed particles had no obvious benefits for behavior, but decreased hairball prevalence. Overall, unlimited hay had the highest benefit for both behavior and gastrointestinal health. Adding iron to the MR did not alter behavior or gastrointestinal health compared with MR without iron supplement. This study demonstrated that different roughage sources, amounts, and particle sizes have different effects on veal calf behavior and gastrointestinal health, and hence on veal calf welfare. Key words: veal calf, behavior, gastrointestinal health, roughage

\section{INTRODUCTION}

Surplus dairy calves are generally transported to fattening farms and reared under intensive conditions for the production of veal. To produce the pale-colored meat preferred by consumers, veal calves are fed a diet low in iron, which typically translates to low levels of solid feed relative to milk replacer (MR) and, in particular, low levels of roughage. The European Council 1997 Directive (EC, 1997) stipulates that veal calves should be fed a minimum of 50 to $250 \mathrm{~g}$ per day of fibrous feed from 8 to 20 wk of age. However, no clarification is made as to which source or particle size of fibers should be fed to veal calves. Moreover, it is unclear whether solid feed amounts stipulated in the European Union (EU) Directive refer to DM or fresh product. Previous research has demonstrated that these amounts are insufficient in preventing the development of abnormal oral behaviors in veal calves (Morisse et al., 1999; Mattiello et al., 2002; Webb et al., 2012). These behaviors are thought to mainly result from a frustrated drive to chew and ruminate on solid feed (Veissier et al., 1998). Abnormal oral behaviors in veal calves include tongue playing and rolling; excessive oral manipulation of trough, bucket, and pen structures; sham chewing; and grazing of the 
coat of other calves (Veissier et al., 1998; Morisse et al., 1999; Webb et al., 2012). Abnormal behaviors are generally considered to be an indication of chronic stress and poor welfare (Broom and Fraser, 2007). Abrasive and coarse feed sources, and longer feed particles may increase chewing and rumination, and consequently reduce abnormal oral behaviors in calves. For example, straw seems more effective than beet pulp in reducing abnormal oral behaviors (Mattiello et al., 2002). Moreover, larger amounts of solid feed, kept constant relative to metabolic weight, were shown to improve chewing and rumination (Webb et al., 2012).

The production of veal and especially the feeding strategies used have been implicated in several gastrointestinal health problems (e.g., abomasal damage, poor rumen development, and in some cases the development of hairballs in the rumen; Morisse et al., 1999; Brscic et al., 2011). In a cross-sectional European study, Brscic and colleagues (2011) showed that veal farms that fed more solid feed were associated with a higher prevalence of abomasal lesions. A link between the provision of solid feed and abomasal damage in veal calves was also confirmed experimentally, although MR provision itself can lead to abomasal damage in veal calves (Breukink et al., 1991; Mattiello et al., 2002). It remains unclear whether certain sources of solid feed may be a greater risk for abomasal damage. Straw, grains, straw pellets, and maize silage (MS) pellets have been associated with abomasal damage (Breukink et al., 1991; Mattiello et al., 2002; Brscic et al., 2011). Rumen development is affected by the fermentation value of the solid feed, with microbial digestion end products, namely VFA, enabling papillae growth (Flatt et al., 1958). In addition, the physical action of the coarse and abrasive solid feed on the rumen wall increases rumen capacity and muscularization (Harrison et al., 1960; Tamate et al., 1962) as well as reduces the incidence of a condition labeled plaque. Plaque involves a layer of particles and debris being stuck to ruminal papillae, which reduces VFA uptake (Haskins et al., 1969; Suárez et al., 2007). Therefore, different sources of solid feed, differing in fermentation value and physical structure, may have different effects on rumen development. Finally, low levels of solid feed in veal calf diets have been associated with ruminal hairball development, which may impair digestion (Morisse et al., 1999).

This study assessed how different sources, amounts, and particle sizes of roughage might affect the behavior and gastrointestinal health of Holstein-Friesian calves, to provide a basis for an animal-friendly feeding strategy. To quantify the effects of roughage supplementation on behavior and health, a control group fed only MR was included. Roughage supplementation usually involves higher iron intake. Therefore, an additional control group was fed MR only, with an iron supplement. This provided a control for potentially confounding effects of iron intake. Finally, a positive control was included in the design to provide a basis for high welfare in the current study. This group of calves was fed hay $(\mathbf{H Y})$ in unlimited quantities. Hay provides both structure and fermentable fiber and should minimize abnormal oral behaviors and enable optimal rumen development.

\section{MATERIALS AND METHODS}

The study was conducted at the experimental cattle farm of Wageningen University and Research Centre (Lelystad, the Netherlands). All procedures met the terms of the Dutch law for animal experiments, which complies with the ETS123 (Council of Europe 1985 and the 86/609/EEC Directive) and was approved by the Wageningen University and Research Centre Committee on Animal Care and Use.

\section{Animals and Management}

Two batches of 150 Holstein-Friesian bull calves (10 $\pm 1 \mathrm{~d} ; 46.1 \pm 0.1 \mathrm{~kg}$ ) were studied in 2 successive experiments, each lasting for 6 mo. Each batch comprised 2 groups of 75 calves housed in separate barns. Each group within each batch comprised 1 pen per treatment. The calves were housed throughout the experiment in the same $3 \times 3-\mathrm{m}^{2}$ pens with wooden slatted floors (5 calves per pen). During the first $6 \mathrm{wk}$ after arrival, partitions (allowing visual and tactile contact between calves) were placed in each pen, separating individual animals to minimize cross-sucking and disease transmission. Partitions were removed at $6 \mathrm{wk}$ and calves were group housed until slaughter at $24 \mathrm{wk}$. The temperature, ranging from 15 to $25^{\circ} \mathrm{C}$, was controlled using mechanical ventilation and heating. Calves were given an antimicrobial treatment when they arrived at the experimental facilities (colistin for $10 \mathrm{~d}$ and oxytetracycline for $5 \mathrm{~d}$ ). Blood samples were taken every $4 \mathrm{wk}$ to monitor hemoglobin levels. Calves were injected with extra iron when required to ensure that average hemoglobin levels were above $4.5 \mathrm{mmol} / \mathrm{L}$ when slaughtered at $24 \mathrm{wk}$ of age (Table 1). This is the minimum level stated in the EU legislation for veal calves.

All calves were bucket fed with MR twice per day at 0700 and $1600 \mathrm{~h}$ following a commercial scheme to produce veal (i.e., starting with $3 \mathrm{~L} / \mathrm{d}$, the milk allowance was increased linearly throughout the study to end at $17 \mathrm{~L} / \mathrm{d}$ ). During the first $6 \mathrm{wk}$, calves were fed starter MR and thereafter, fattening MR (Table 2). The powder-to-water ratio was, on average, 1:8 at the beginning and 1:5.8 at the end of the study. The treat- 
Table 1. Average daily gain from 2 to 24 wk of age and hemoglobin levels at 24 wk of age in veal calves assigned to different feeding strategies $(\mathrm{n}=300)$

\begin{tabular}{|c|c|c|c|c|}
\hline \multirow[b]{2}{*}{ Feed } & \multicolumn{2}{|c|}{$\mathrm{ADG}(\mathrm{g} / \mathrm{d})$} & \multicolumn{2}{|c|}{ Hemoglobin $(\mathrm{mmol} / \mathrm{L})$} \\
\hline & Mean & SEM & Mean & SEM \\
\hline \multicolumn{5}{|l|}{ Type of feed } \\
\hline Straw & $1,149^{\mathrm{a}}$ & 7.7 & $4.8^{\mathrm{a}}$ & 0.18 \\
\hline Maize silage & $1,212^{\mathrm{b}}$ & & $7.1^{\mathrm{c}}$ & \\
\hline Maize cob silage & $1,212^{\mathrm{b}}$ & & $7.1^{\mathrm{c}}$ & \\
\hline Milk only & $1,121^{\mathrm{a}}$ & 15.4 & $4.6^{\mathrm{a}}$ & 0.09 \\
\hline Milk + iron supplement & $1,134^{\mathrm{a}}$ & & $5.9^{\mathrm{b}}$ & \\
\hline Hay & $1,260^{\mathrm{c}}$ & & $5.9^{\mathrm{b}}$ & \\
\hline \multicolumn{5}{|l|}{ Feed particle size } \\
\hline Chopped & 1,183 & 6.3 & 5.4 & 0.07 \\
\hline Ground & 1,199 & & 5.6 & \\
\hline \multicolumn{5}{|l|}{ Amount of feed } \\
\hline $250 \mathrm{~g}$ of $\mathrm{DM} / \mathrm{d}$ & $1,169^{\mathrm{a}}$ & 6.3 & $5.2^{\mathrm{a}}$ & 0.07 \\
\hline $500 \mathrm{~g}$ of $\mathrm{DM} / \mathrm{d}$ & $1,213^{\mathrm{b}}$ & & $5.8^{\mathrm{b}}$ & \\
\hline
\end{tabular}

${ }^{\mathrm{a}-\mathrm{c}}$ Means within a column and within type of feed and amount of feed categories with different superscripts differ significantly $(P<0.05)$.

ments were started from the second week after arrival at the experimental farm. Before that, all calves were fed only MR. Roughage was fed in the morning after MR was consumed.

\section{Treatments}

The study was a $3 \times 2 \times 2$ complete factorial design with roughage supplement source: wheat straw (STR) versus MS versus maize cob silage (MC), amount: 250 versus $500 \mathrm{~g}$ of $\mathrm{DM} / \mathrm{d}$, and particle size: chopped (4 to $5 \mathrm{~cm})$ versus ground $(1 \mathrm{~cm})$ as factors. Composition of roughage used is shown in Table 3. Dried MS and $\mathrm{MC}$ were used to improve the quality of the grinding process. Maize silage and $\mathrm{MC}$ were dried in a dryer at $350^{\circ} \mathrm{C}$ for $6 \mathrm{~min}$. Three control treatments were included: MR only, MR plus an iron supplement diluted in the milk $(\mathbf{M R}+)$, and a diet of MR plus ad libitum HY. The factorial design involved a total of 300 animals (240 treated and 60 control) in 15 groups of 4 pens each. The MR+ calves received $58 \mathrm{mg}$ of $\mathrm{Fe} / \mathrm{kg}$ of $\mathrm{DM}$ in the starter milk, and $116 \mathrm{mg}$ of $\mathrm{Fe} / \mathrm{kg}$ of $\mathrm{DM}$ in the fattening milk (Table 2).

\section{Measurements}

Calves were weighed at arrival and before slaughter, and ADG is shown in Table 1. Milk refusals were

Table 2. Composition (\%, unless otherwise specified) of milk replacers used in the study ${ }^{1}$

\begin{tabular}{lcc}
\hline & \multicolumn{2}{c}{ Milk replacer } \\
\cline { 2 - 3 } Item & Starter & Fattening \\
\hline Composition & & \\
Skimmed milk powder & 51 & 27 \\
Whey powder & - & 21 \\
Delactosed whey powder ${ }^{2}$ & - & 6 \\
Whey powder concentrate-35 & 4 & 4.5 \\
Starch & 18 & 21.5 \\
Fat & 1 & - \\
Vitamins/minerals & & 97.0 \\
Chemical composition & 96.7 & 9.9 \\
DM & 53.3 & 20.5 \\
Fe (mg/kg) & 22.5 & $<0.5$ \\
CP (\% of DM) & $<0.5$ & 7.3 \\
Crude fiber (\% of DM) & 7.0 & 20.7 \\
Crude ash (\% of DM) & 17.9 & 18.9 \\
Fat (\% of DM) & 18.8 & \\
ME (MJ/kg) & & 20 \\
\hline
\end{tabular}

${ }^{1}$ Composition values were provided by the feed manufacturer. Starter milk replacer was fed for the first 6 wk and fattening milk replacer was fed to the calves for the rest of the study.

${ }^{2}$ Whey powder with lactose removed using crystallization.

${ }^{3}$ Whey powder concentrate with $35 \%$ protein, created using infiltration. 
Table 3. Composition ( $\mathrm{g} / \mathrm{kg}$ of DM, unless otherwise specified) of roughages supplemented to milk replacer during the study ${ }^{1}$

\begin{tabular}{|c|c|c|c|c|c|c|c|}
\hline Item & \multicolumn{6}{|c|}{ Roughage supplement $^{2}$} & Hay \\
\hline DM, \% & $91 \pm 0.9$ & $91 \pm 0.6$ & $86 \pm 1.1$ & $85 \pm 1$ & $91 \pm 0.4$ & $90 \pm 0.4$ & $85 \pm 1.1$ \\
\hline $\mathrm{CP}$ & $41 \pm 4$ & $45 \pm 4$ & $79 \pm 1$ & $78 \pm 1$ & $86 \pm 1$ & $86 \pm 1$ & $146 \pm 2$ \\
\hline Crude fiber & $415 \pm 7$ & $395 \pm 6$ & $168 \pm 3$ & $163 \pm 3$ & $100 \pm 3$ & $104 \pm 3$ & $287 \pm 6$ \\
\hline Crude ash & $106 \pm 2$ & $105 \pm 3$ & $51 \pm 1$ & $50 \pm 1$ & $34 \pm 1$ & $33 \pm 1$ & $93 \pm 5$ \\
\hline $\mathrm{OEB}^{6}$ & $-31 \pm 2$ & $-30 \pm 2$ & $-44 \pm 0$ & $-44 \pm 0$ & $-28 \pm 1$ & $-29 \pm 1$ & $-4 \pm 3$ \\
\hline $\mathrm{ME}^{7}(\mathrm{MJ} / \mathrm{kg}$ of DM) & 5.53 & 5.50 & 11.04 & 11.10 & 11.95 & 12.45 & 9.68 \\
\hline
\end{tabular}

${ }^{1}$ Mean analysis of 6 samples taken every $4 \mathrm{wk}$ throughout the experiment. Roughage treatments started at $2 \mathrm{wk}$.

${ }^{2} \mathrm{STR}=$ straw $-\mathrm{G}=$ ground roughage (columns without $-\mathrm{G}$ stand for chopped); MS = maize silage; $\mathrm{MC}=$ maize cob silage.

${ }^{3} \mathrm{VC}-\mathrm{os}=\mathrm{OM}$ fermentability.

${ }^{4}$ VEVI $=$ net energy for growing cattle according to Dutch standards (Van Es, 1978).

${ }^{5} \mathrm{DVE}=$ true protein digested in the small intestine according to Dutch standards (Tamminga et al., 1994).

${ }^{6} \mathrm{OEB}=$ rumen degraded protein balance according to Dutch standards (Tamminga et al., 1994).

${ }^{7}$ Metabolizable energy was calculated from averages.

weighed daily, but were below $0.5 \%$, on average. Therefore, provision and intake were considered identical. The chemical composition of the milk was reported by the feed manufacturer (Table 2). Roughage refusals were collected daily but only weighed weekly. Roughage intake was calculated per pen per week. Roughage samples were collected on a weekly basis. The samples were pooled and analyzed by a private laboratory every 4 wk (Table 3).

Behavioral Observations. Calf behaviors (Table 4) were recorded by 4 observers. Direct observations were done across 1 wk at 12 and 22 wk of study. The observer sat on a high chair and observed 2 pens simultaneously. Observations were done using instantaneous scan sampling at a 2-min interval for $2 \mathrm{~h}$ : "a whole group of subjects is rapidly scanned ... at regular intervals and the behavior of each individual at that instant is recorded" (Martin and Bateson, 2001). Observations were carried out during 3 periods: 0630 to $0830 \mathrm{~h}, 1100$ to $1300 \mathrm{~h}$, and 1530 to $1730 \mathrm{~h}$.

Gastrointestinal Health Measurements. Calves were slaughtered at $24 \mathrm{wk}$ in an experimental slaughterhouse $3 \mathrm{~km}$ away from the experimental cattle farm. The rumens and abomasa were collected, rumen fluid was extracted and the rumens and abomasa were rinsed under water for inspection by a veterinarian pathologist, and weighed. The presence of ruminal hairballs and abomasal lesions in the pyloric area was recorded. Lesions were classified as ulcers, erosions, or scars. Ulcers were characterized by focal loss or necrosis of the epithelial layer down to the submucosal or muscular layer of the stomach wall. Erosions were characterized as inflammations with partial superficial or profound loss of epithelium without clear disruption of the epithelial layer. Scars were characterized as focal, longitudinal, or round fibrous contractions of the mucosa. The number of hairballs and abomasal lesions was recorded. For hairballs, the diameter of the biggest hairball was measured, and for lesions, the size was calculated as horizontal diameter $\times$ vertical diameter. When both diameters of a given lesion were less than $0.5 \mathrm{~cm}$, an arbitrary size of $0.1 \mathrm{~cm}^{2}$ was allocated to the lesion. Finally, rumen fluid $\mathrm{pH}$ was recorded.

\section{Statistical Analysis}

Roughage intake up to and including wk 12, as well as wk 12 alone, was analyzed, using a linear model of

Table 4. Ethogram of oral behaviors, based on de Wilt (1985)

\begin{tabular}{|c|c|}
\hline Behavior & Description \\
\hline Chewing and rumination & $\begin{array}{l}\text { Repetitive movements of upper and lower jaw moved in a regular fashion in the lateral plane, } \\
\text { with or without substrate in mouth }\end{array}$ \\
\hline Tongue play & $\begin{array}{l}\text { Tongue playing/rolling; repeatedly turning, rolling, and unrolling tongue extended outside } \\
\text { or inside of mouth }\end{array}$ \\
\hline Oral manipulation of trough & Licking, nibbling, or sucking bucket or trough \\
\hline Oral manipulation of pen & Licking, nibbling, or sucking partitions, wall, or floor of pen \\
\hline Oral manipulation of pen mate & Licking, nibbling, or sucking the coat or part of another calf in the pen \\
\hline Groom & Tongue is extended and shifted across own body repeatedly \\
\hline
\end{tabular}


variance (ANOVA) with fixed factors source, amount and particle size, as well as 2-way interactions between them. Post-hoc comparisons were carried out using Fisher's least significant difference method.

All other data were analyzed in 2 steps, involving separate analyses: (1) effects of the 3 treatments of the factorial design (i.e., source, amount, and particle size) were analyzed and (2) levels of the factor source were compared with the 3 added controls. The first step did not involve the 3 added controls. The second did involve the 3 added controls and depended upon the results of the first step as explained below.

Factorial Design. The setup was a $3 \times 2 \times 2$ factorial design with source, amount, and particle size of roughage as the factors. Behavioral and gastrointestinal health data were first analyzed for effects of these factors.

Behavioral observations were expressed as proportions of total scans, per age (wk 12 and 22), and averaged per pen. Data for the presence of abomasal lesions and ruminal hairballs were expressed as binary data. Data for the number of lesions or hairballs were expressed as counts. Data related to the size of lesions were treated as continuous data.

Proportions were analyzed at pen level with a logistic regression model, an instance of a generalized linear model comprising an additional multiplicative (over) dispersion parameter in the binomial variance function. Binary and count data were analyzed at animal level with a generalized linear mixed model, comprising random pen effects. For the binary data, a Bernoulli distribution and logit link function were specified. For the count data, a Poisson distribution and logarithmic link function were specified. In addition, for count data, the model included a multiplicative (over)dispersion parameter in the Poisson variance function. Continuous data were analyzed with a linear mixed model, comprising random pen effects.

All models included fixed (i.e., systematic nonrandom) main effects for batch and main effects and interactions for the experimental factors source, amount, and particle size. Parameters were estimated by maximum quasi-likelihood for generalized linear models (McCullagh and Nelder, 1989), penalized quasi-likelihood for generalized linear mixed models (Breslow and Clayton, 1993), and REML for linear mixed models (McCulloch et al., 2008).

For observations with a high frequency of zeros, to the extent that the average value for an entire treatment group was zero, and when the algorithm that was used failed to converge, nonparametric significance tests were used to compare treatments. Thus, prevalence of abomasal scars and ruminal hairballs were analyzed with Fisher's exact test. The number and size of scars as well as hairball number and maximum hairball diameter were analyzed using the Mann-Whitney U test (Wilcoxon's 2-sample test).

Pairwise Comparisons with Controls. Appropriate tables of means were identified for further analysis through pairwise comparisons with Fisher's least significant difference method. For instance, when no significant $(P>0.05)$ interactions involving factor source were found in the first step, in the second step, pairwise comparisons were performed between the means of the added controls and the 3 means for the levels of factor source. However, if an interaction between source and amount was found, means for the controls were compared with the means for the combinations of source and amount. The basic model used for pairwise comparisons comprised a single factor at 15 levels: the 3 added controls plus the 12 combination of factors source, amount, and particle size from the $3 \times$ $2 \times 2$ factorial design. All statistical analyses were run in GenStat (VSN International Ltd., 2012).

\section{RESULTS}

\section{Roughage Intake}

Average intakes of STR, MS, and MC are shown in Figure 1A and 1B. An interaction was observed between source and amount for roughage intake up to and including study wk $12(P=0.006)$. Calves fed $250 \mathrm{~g}$ of STR DM/d had lower roughage intakes compared with calves fed $250 \mathrm{~g}$ of MS DM/d $(P=0.005)$ or $250 \mathrm{~g}$ of $\mathrm{MC} \mathrm{DM} / \mathrm{d}(P=0.029)$. Calves fed either $500 \mathrm{~g}$ of STR or $\mathrm{MC} \mathrm{DM} / \mathrm{d}$ had lower roughage intakes compared with those fed $500 \mathrm{~g}$ of MS DM/d $(P<0.001)$. Roughage intake during the first 12 wk of study was similar for calves fed 250 or $500 \mathrm{~g}$ of STR or MC DM/d $(P>$ $0.1)$, but was higher in calves fed $500 \mathrm{~g}$ of MS DM/d $(P$ $<0.001)$. However, during wk 12, calves fed STR, MS, or $\mathrm{MC}$ consumed more in the $500 \mathrm{~g}$ of $\mathrm{DM} / \mathrm{d}$ treatment compared with the $250 \mathrm{~g}$ of $\mathrm{DM} / \mathrm{d}$ treatment $(P<$ 0.001). Therefore, treatments 250 and $500 \mathrm{~g}$ of $\mathrm{DM} / \mathrm{d}$ were considered different for behavioral measurements carried out at 12 wk. Calves fed ad libitum HY reached $250 \mathrm{~g}$ of $\mathrm{DM} / \mathrm{d}$ after $5 \mathrm{wk}$ and $500 \mathrm{~g}$ of $\mathrm{DM} / \mathrm{d}$ after 10 wk (Figure 1C). At 22 wk, these calves consumed 1,125 $\mathrm{g}$, on average.

\section{Behavioral Observations}

Results of pairwise comparisons between the 3 levels of the factor source (i.e., STR, MS, and MC) and the 3 control treatments (i.e., MR, MR+, and HY) are shown in Figure 2 (12 wk) and Figure 3 (22 wk).

$12 w k$. An interaction was found between roughage source and amount $(P=0.008)$ for chewing and 

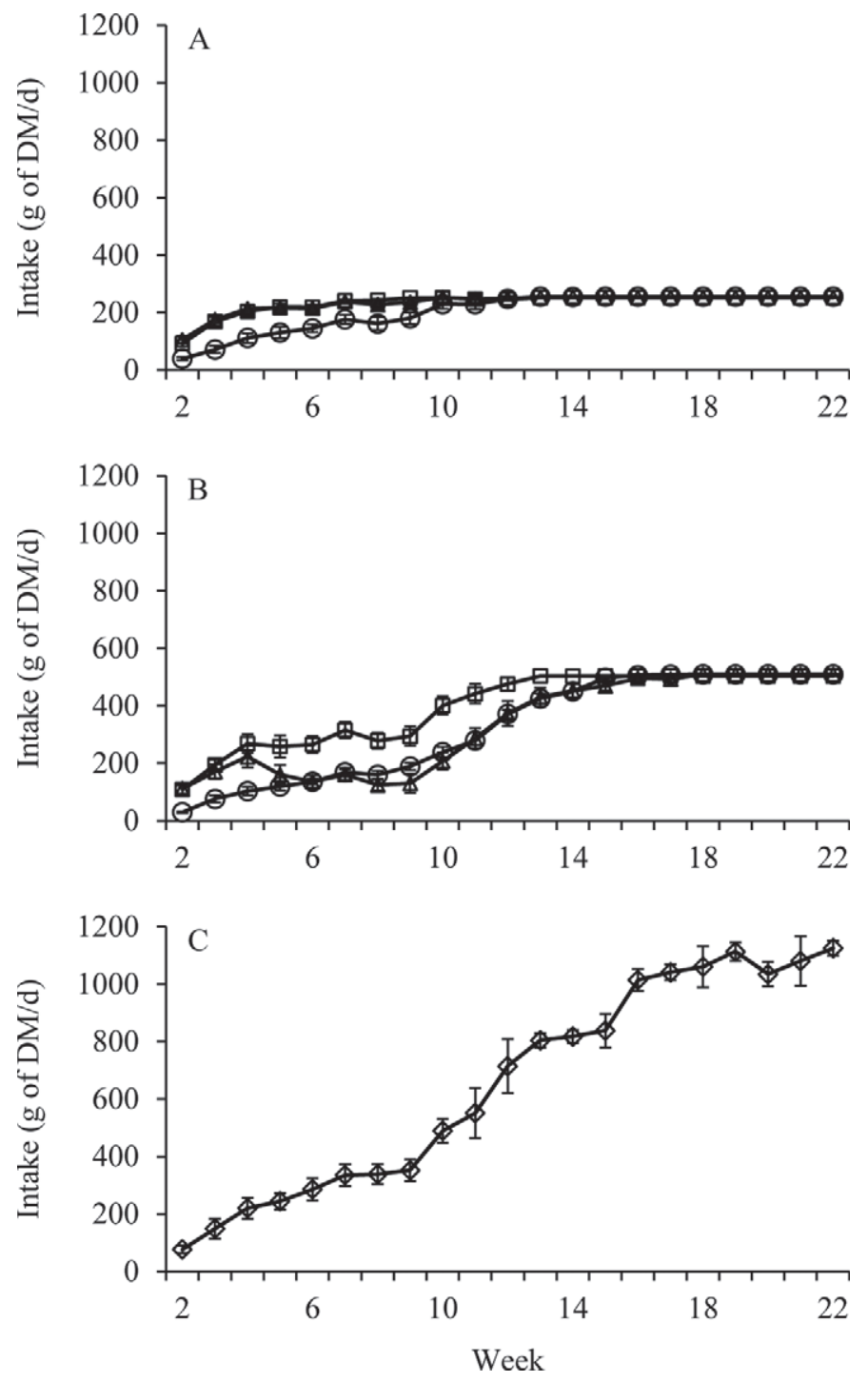

Figure 1. Mean ( \pm SEM) intake of straw (circles), maize silage (squares), and maize cob silage (triangles), or hay (diamonds) across weeks in calves fed 250 (A) or 500 (B) g of DM/d, or hay ad libitum (C). Roughage provision started at 2 wk. Milk replacer was switched from starter to fattening after the initial $6 \mathrm{wk}$.

rumination. Within the MS and MC treatments, calves fed $500 \mathrm{~g}$ of $\mathrm{DM} / \mathrm{d}$ chewed more than calves fed 250 $\mathrm{g}$ of $\mathrm{DM} / \mathrm{d}(P<0.001$ and $P=0.001$, respectively $)$, whereas chewing was similar with the 2 amounts of STR $(P=0.18)$. Moreover, regardless of the amount, calves fed STR chewed more than calves fed MS or MC, and calves fed MS chewed more than calves fed MC $(P<0.05)$. Particle size tended to affect chewing and rumination $(P=0.088)$. Calves fed chopped roughage $(10.1 \pm 0.76 \%$ of total scans) tended to chew more than calves fed ground roughage $(8.5 \pm 0.68 \%$ of total scans). An effect of source of roughage was found on tongue playing $(P=0.004)$. Calves fed STR tongue played less than calves fed MS or MC. Both source $(P$ $=0.018)$ and amount $(P=0.009)$ of roughage affected oral manipulation of the trough. Calves fed STR orally manipulated the trough less than calves fed MC. Calves fed $250 \mathrm{~g}$ of $\mathrm{DM} / \mathrm{d}$ roughage $(11.1 \pm 0.7 \%$ of total scans) orally manipulated the trough more often than calves fed $500 \mathrm{~g}$ of $\mathrm{DM} / \mathrm{d}(8.2 \pm 0.6 \%$ of total scans $)$. Source, amount, and particle size $(P>0.1)$ of roughage did not affect oral manipulation of the pen. Similarly, no effect of source, amount, or particle size $(P>0.1)$ was found on oral manipulation of pen mates. No effect of source or particle size $(P>0.1)$ was found on grooming. However, a tendency was observed for calves fed $250 \mathrm{~g}$ of $\mathrm{DM} / \mathrm{d}(3.9 \pm 0.22 \%$ of total scans $)$ to groom less compared with calves fed $500 \mathrm{~g}$ of $\mathrm{DM} / \mathrm{d}(4.7 \pm$ $0.24 \%$ of total scans; $P=0.083$ ).

$22 w k$. At $22 \mathrm{wk}$, the source of roughage affected chewing and rumination $(P<0.001)$ as well as tongue playing $(P=0.036)$. Calves fed STR chewed more than those fed MS or MC and tongue played less than calves fed MS. An effect of amount of roughage was found on oral manipulation of the trough $(P=0.036)$. Calves fed $250 \mathrm{~g}$ of $\mathrm{DM} / \mathrm{d}(13.4 \pm 0.8 \%$ of total scans) orally manipulated the trough more often than calves fed $500 \mathrm{~g}$ of DM/d (10.8 $\pm 0.6 \%$ of total scans). Calves fed $250 \mathrm{~g}$ of DM/d ( $8.2 \pm 0.4 \%$ of total scans $)$ tended $(P=0.053)$ to orally manipulate the pen more than calves fed 500 $\mathrm{g}$ of $\mathrm{DM} / \mathrm{d}(6.9 \pm 0.4 \%$ of total scans). The source was found to affect oral manipulation of pen mates $(P=$ 0.011), with calves fed STR or MS orally manipulating pen mates less than calves fed MC. Finally, the source, amount and particle size $(P>0.1)$ of roughage had no effect on grooming.

\section{Gastrointestinal Health}

Results of pairwise comparisons carried out between the 3 levels of the factor source (STR, MS, and MC) and the 3 control treatments (MR, MR+, and HY) on gastrointestinal health measurements are described in Table 5 .

Abomasum. The source of roughage affected the weight of the abomasum $(P=0.001)$, which was lighter in calves fed STR than in those fed MS or MC. None of the factors had an effect on ulcer or scar prevalence $(P$ $>0.1)$. The source of roughage tended to have an effect on the prevalence of erosions $(P=0.057)$, with the STR treatment resulting in a higher erosion prevalence than MS or MC treatments. An interaction between amount and source of roughage on the number of abomasal ulcers was found $(P=0.005)$. Calves fed 250 $\mathrm{g}$ of MS DM/d had fewer ulcers than calves fed STR $(P=0.001)$ or MC $(P=0.044)$. Moreover, calves fed MS had more ulcers when fed 500 instead of $250 \mathrm{~g}$ of 

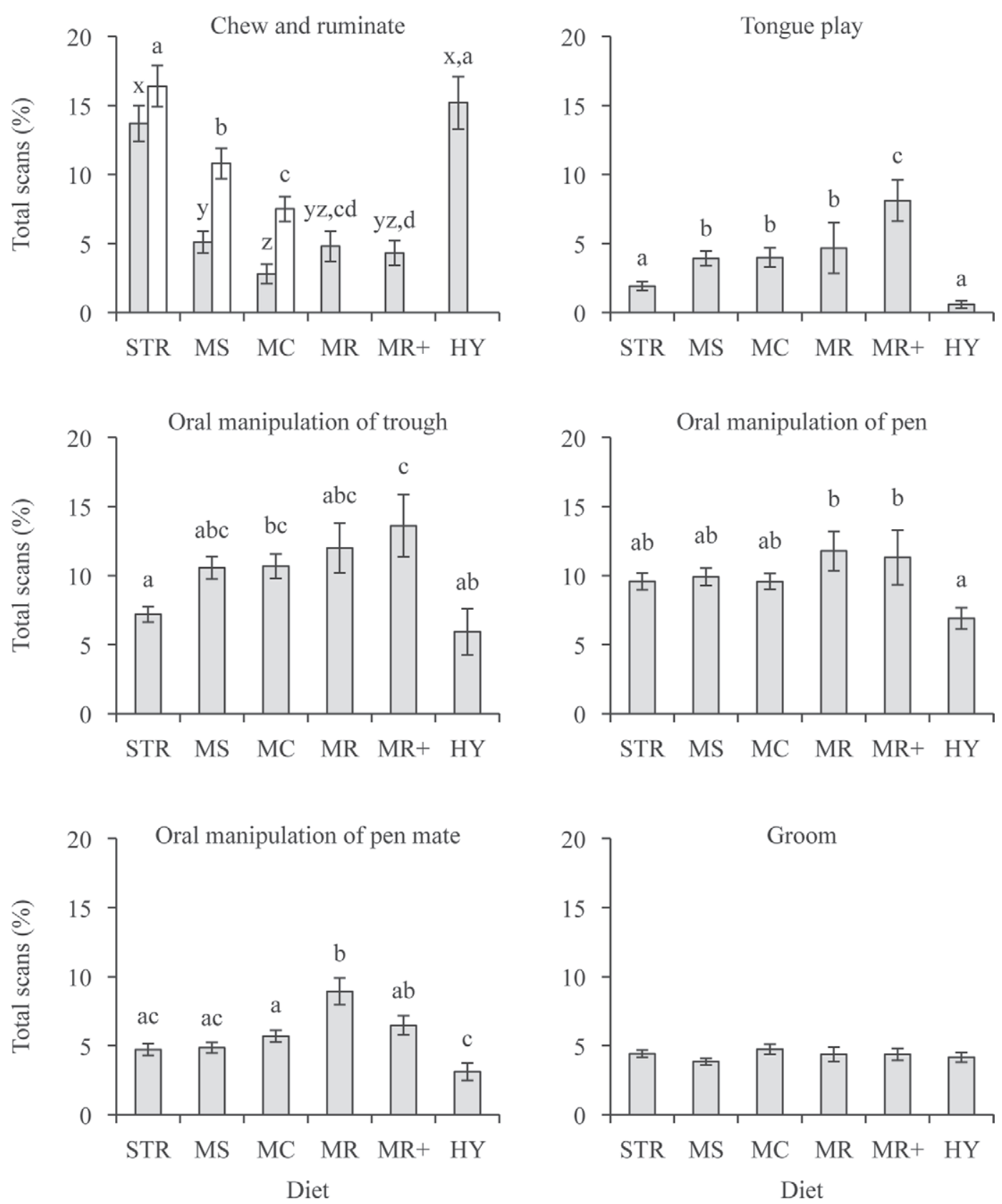

Figure 2. Mean \pm SEM for behaviors recorded at $12 \mathrm{wk}$ in calves fed straw (STR), maize silage (MS), maize cob silage (MC), milk replacer only $(\mathrm{MR})$, milk replacer plus iron supplement $(\mathrm{MR}+)$, or hay ad libitum $(\mathrm{HY} ; \mathrm{n}=300)$. Bars with different letters differ $(P<0.05)$. For chewing, interactions existed between source and amount for STR, MS, and MC. Differences between levels of the factor source and controls are, therefore, divided between 250 (gray, letters $\mathrm{x}-\mathrm{z}$ ) and $500 \mathrm{~g}$ of DM/d (white, letters a-d) from STR, MS, and MC. For MR, MR+, and HY, there were no factors of amount so 1 gray bar is shown.

roughage $\mathrm{DM} / \mathrm{d}(P=0.009)$. An interaction between source and amount of roughage was found on the number of erosions $(P=0.011)$. With treatments including $250 \mathrm{~g}$ of DM/d, calves fed MC had fewer erosions than calves fed STR $(P=0.004)$ or MS $(P=0.028$; Table $5)$. With treatments including $500 \mathrm{~g}$ of $\mathrm{DM} / \mathrm{d}$, calves fed MS had fewer erosions than calves fed STR $(P=$
$0.007)$ or $\mathrm{MC}(P=0.042)$ (Table 5$)$. Finally, calves fed a smaller amount of MC had fewer erosions $(P=$ 0.012 ; Table 5). No effect of source, amount, or particle size was found on the number of scars $(P>0.1)$. The amount of roughage affected ulcer size $(P=0.015)$, which was smaller in calves fed $250 \mathrm{~g}$ of $\mathrm{DM} / \mathrm{d}(1.3 \pm$ $\left.0.2 \mathrm{~cm}^{2}\right)$ than in calves fed $500 \mathrm{~g}$ of DM/d $(2.0 \pm 0.2$ 

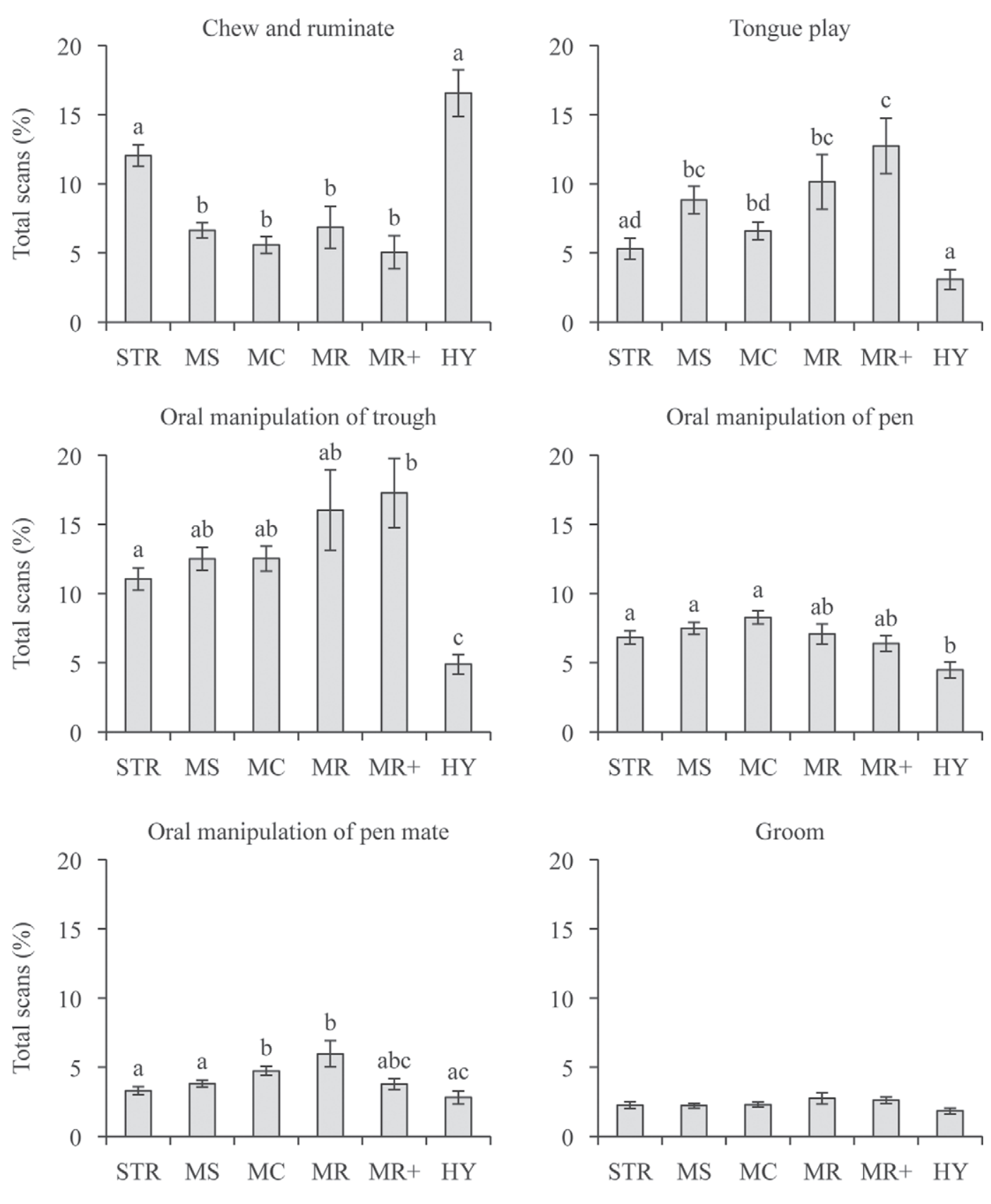

Diet

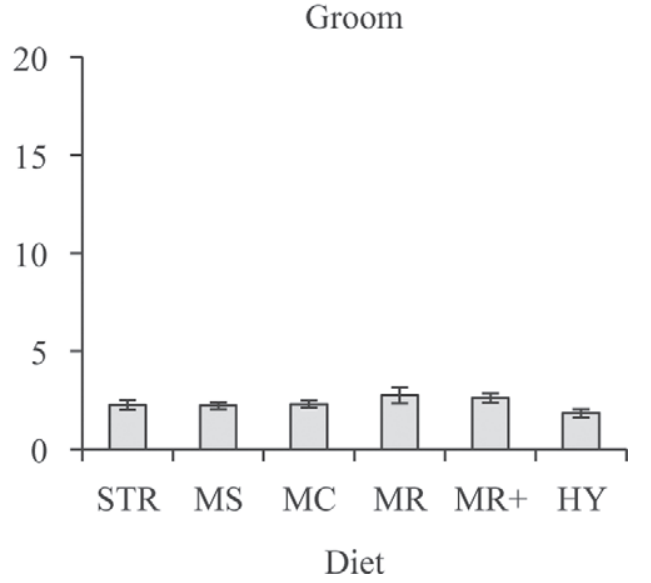

Figure 3. Mean \pm SEM for behaviors recorded at $22 \mathrm{wk}$ in calves fed straw (STR), maize silage (MS), maize cob silage (MC), milk replacer only (MR), milk replacer plus iron supplement $(\mathrm{MR}+)$, or hay ad libitum $(\mathrm{HY} ; \mathrm{n}=300)$. Bars with different letters $(\mathrm{a}-\mathrm{c})$ differ $(P<0.05)$.

$\left.\mathrm{cm}^{2}\right)$. Moreover, roughage source affected erosion $(P=$ $0.001)$ and scar size $(P=0.030)$. Calves fed STR had larger erosions than calves fed MS or MC, and larger scars than calves fed MC.

Rumen. Both source $(P<0.001)$ and amount $(P<$ 0.001) affected rumen weight. Calves fed STR had lighter rumens compared with calves fed MS or MC. Calves fed $500 \mathrm{~g}$ of $\mathrm{DM} / \mathrm{d}(2,120.0 \pm 34.6 \mathrm{~g})$ had heavier rumens than calves fed $250 \mathrm{~g}$ of roughage DM/d $(1,852.0 \pm 33.5$ $\mathrm{g})$. None of the factors had an effect on ruminal $\mathrm{pH}(P$ $>0.1)$. The prevalence of hairballs was affected by both source $(P<0.001)$ and particle size $(P=0.011)$. Fewer calves fed STR had hairballs compared with those fed MS and MC, and fewer calves fed MS had hairballs compared with MC. Calves fed chopped roughage were less likely to have hairballs in their rumen ( $9 \%$ calves) 
Table 5. Results of pairwise comparisons between the levels of the factor source [straw (STR), maize silage (MS), and maize cob silage (MC)] and the control treatments [milk replacer $(\mathrm{MR}), \mathrm{MR}$ with an iron supplement (MR+), and ad libitum hay (HY)] on gastrointestinal health in 300 veal calves (24 wk of age)

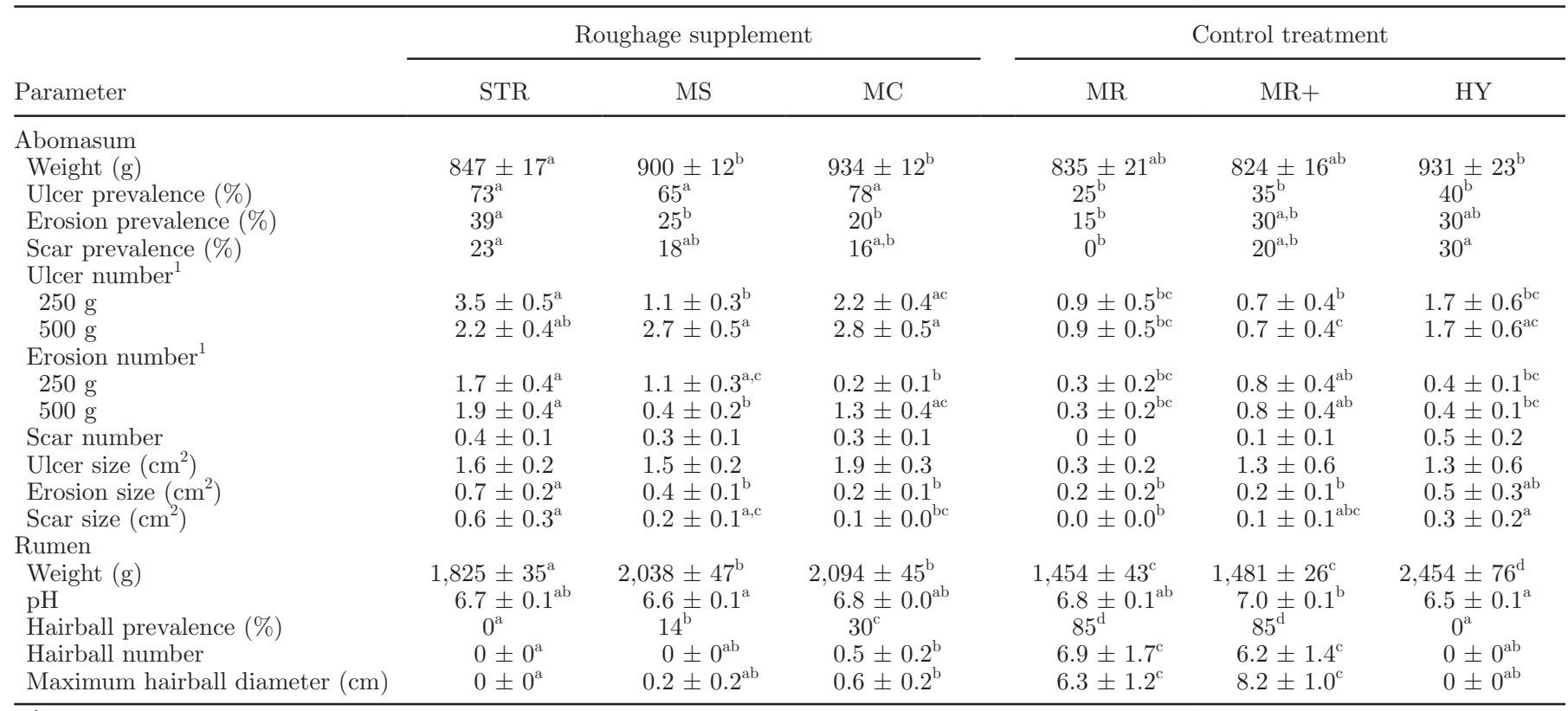

${ }^{\mathrm{a}-\mathrm{d}}$ Means or percentages within a row with different superscripts differ $(P<0.05)$.

${ }^{1}$ Interaction found between source and amount $(P<0.05)$.

compared with calves fed ground roughage (20\% calves; $P=0.008)$. The source of roughage affected hairball number $(P=0.018)$, with calves fed STR having fewer hairballs than calves fed MC.

\section{DISCUSSION}

This study to some extent confirmed the previously described conflict between behavior and abomasal health when feeding roughage to veal calves (Mattiello et al., 2002). Roughage sources and amounts that improved behavior (e.g., increased chewing and rumination and decreased abnormal oral behaviors) exacerbated abomasal damage. The present results indicate that STR provision, probably due to its coarser nature, was more efficient in increasing chewing and rumination in the calves than MS and MC, and subsequently better at reducing tongue playing, consistent with previous findings (Mattiello et al., 2002). Moreover, increasing the roughage ration from 250 to $500 \mathrm{~g}$ of $\mathrm{DM} / \mathrm{d}$ also increased chewing and rumination and decreased abnormal oral behaviors. Roughage provision in itself and larger amounts of roughage were associated with worse abomasal damage in this study, as shown in previous research (Breukink et al., 1991; Mattiello et al., 2002). Calves fed only MR also showed some level of abomasal damage, consistent with previous research (Breukink et al., 1991; Mattiello et al., 2002). The proposed ex- planation for this damage is that overloading of the abomasum, due to large quantities of milk fed to calves in few meals, causes stretching of the wall and local ischemia (Breukink et al., 1991). The provision of STR, in particular, led to increased erosion prevalence, number, and size compared with most other treatments. Exacerbation of ulcers, however, was associated with all roughage supplements. This difference in factors affecting erosions and ulcers may suggest that they have separate etiologies. This was previously suggested, due to a difference in numbers and distribution of erosions and ulcers in veal calf abomasa (Wiepkema et al., 1987). The present study suggests that STR and HY lead to increased scar prevalence, number, and size, compared with MR. Wiepkema and colleagues (1987) suggested that scars were healed ulcers, based on distribution and numbers. Proposed factors involved in the etiology of abomasal ulceration in beef and veal calves include the abrasive action of coarse feed stuffs and hair or hairballs in the abomasum (Tulleners and Hamilton, 1980; Katchuik, 1992; Cozzi et al., 2002; Mattiello et al., 2002), as well as the transitional phase between preruminant and ruminant digestion, hence forestomach development (Jelinski et al., 1996). Roughage that could be characterized as coarser, such as STR, did seem to lead to worse abomasal damage, at least for parameters relating to erosions, and this would somewhat be consistent with the "abrasion theory" (Jelinski 
et al., 1996). If the abrasive nature of roughage was one of the main factors leading to abomasal damage, then one would expect particle size to play a role, which was not seen in the present study. Straw provision also led to the smallest rumen weight. Therefore, poor rumen development could also be a factor relating to abomasal damage in veal calves (Berends et al., 2012). This is consistent with the ad libitum HY ration resulting in the lowest damage for ulcer parameters, because HY provision resulted in the heaviest rumens. Rumen development could protect, to some extent, against exacerbation of abomasal damage by minimizing entry of underdigested coarse feed particles into an already sensitized abomasum. If this were the case, greater amounts of roughage, leading to heavier rumens, should have been associated with reduced abomasal damage. In the present study, the opposite was found: ulcers were larger when more roughage was provided (500 compared with $250 \mathrm{~g}$ of $\mathrm{DM} / \mathrm{d}$ ), a greater number of ulcers was present in calves fed more MS, and a greater number of erosions was present in calves fed more MC. These findings are consistent with Brscic et al. (2011). We, therefore, suggest that abomasal lesions, whether ulcers or erosions, may come about from a combination of factors, including (1) overloading of the abomasum, resulting in local ischemia and subsequent lesions; (2) exacerbation of existing damage due to the passage of underdigested feed particles from a poorly developed rumen to a sensitized abomasum; and (3) exacerbation of existing damage with coarse feed stuffs due to their greater abrasive quality. The exact mechanisms involved in the etiology of erosions and ulcers in veal calves, whether similar or not, should be investigated further in the future.

Particle size of roughage in the present study only had an effect on hairball prevalence, with chopped roughage resulting in a lower prevalence compared with ground roughage. Morisse et al. (1999) suggested that ruminal hairballs in calves were minimized by continuous removal of ingested hair as a result of good rumen motility. Larger particles were previously found to have a greater abrasive value than smaller particles of feed (Greenwood et al., 1997). In addition, larger particles were found to result in higher ruminal fluid $\mathrm{pH}$, light gray epithelial layers, smaller papillae, a larger reticulorumen, and a smaller and lighter omasum, but no effect of particle size was found on rumen or abomasum weight (Greenwood et al., 1997; Beharka et al., 1998), the latter being consistent with the present findings. Moreover, although rumen papillae grow in response to microbial fermentation end products, mainly butyrate and propionate, rumen capacity and muscularization can be significantly increased by inert materials through physical stimulation alone (Harrison et al.,
1960; Tamate et al., 1962). Larger particles, also because of a higher abrasive value, may additionally lead to the physical removal of particles wedged between papillae, including feed particles, dead epithelial cells, and ingested hair (Greenwood et al., 1997). Therefore, by increasing rumen muscularization and physical removal of particles, larger feed particles would reduce the incidence of hairballs significantly, which is what the present findings point toward, and which is consistent with the hypothesis of Morisse et al. (1999). The different roughage sources also had a marked effect on hairball development, with STR and HY provision resulting in the absence of ruminal hairballs. These 2 types of roughage most likely had a higher abrasive value compared with MS and MC.

A larger particle size was expected to increase rumination (Heinrichs, 2005), and this was found in the present study. In contrast with expectation based on previous research, the current study did not show that larger amounts of STR increased chewing and rumination levels (Mattiello et al., 2002). Increased levels of chewing and rumination in response to greater amounts were, however, found in calves fed MS or MC. The provision of MS or MC resulted in similar behavior and gastrointestinal health, but for a few exceptions. At 12 wk, MS provision was associated with higher chewing and rumination levels compared with $\mathrm{MC}$, which could suggest that MS better met the chewing and rumination needs of calves. However, calves fed MC had a lower intake at the beginning of the study, which would explain why chewing was lower, and why chewing differences disappeared at 22 wk when intake was similar. Maize cob silage also resulted in higher oral manipulation of pen mates at $22 \mathrm{wk}$. Oral manipulation of pen mates has been suggested to represent redirected feed searching (Mattiello et al., 2002), which might indicate that calves fed MC in the current study were more frustrated from limited feed ration than calves fed MS, at 22 wk. Chewing tended to be lower in the MC-fed calves at 22 wk. Straw and HY treatments also resulted in reduced oral manipulation of pen mates, hence lower redirected feed searching. Both MS and MC resulted in heavier abomasum and rumen weights than those of STR-fed calves. As the rumen wall was probably physically stimulated more when a more abrasive roughage was provided (Greenwood et al., 1997), it is believed that STR was more likely to lead to a higher muscularization than MS or MC. Maize silage and MC might have led to higher VFA production because of a lower crude fiber and higher CP content compared with STR, and would have most likely led to greater papillae growth. Furthermore, differences in rumen weight may reflect the lower STR intake at the beginning of the study compared with MS and MC. 
Not many differences were observed between calves fed MR or MR+, for both behavior and gastrointestinal health parameters. Calves fed MR+ showed higher levels of tongue playing at $12 \mathrm{wk}$ compared with calves fed MR. Iron deficiency anemia in rats and humans can result in lower activity levels (Lozoff and Brittenham, 1986; Felt and Lozoff, 1996), which might explain the increase in tongue playing in calves fed $\mathrm{MR}+$ compared with calves fed MR. However, it does not explain why both liquid-fed treatments did not differ for any other behavioral measurement.

Calves fed unlimited HY reached an intake of over 4.5 times the EU minimum requirement for fibrous feed (i.e., $1,125 \mathrm{~g}$ of $\mathrm{DM} / \mathrm{d}$ ) on top of MR. Hay contains relatively high levels of iron and is, therefore, incompatible with the production of (white) veal. Unlimited supply of HY, however, resulted in the most chewing and rumination, the least tongue playing, and the least oral manipulation of the environment, including pen structure, trough, and pen mates. It also resulted in the heaviest rumens, the absence of ruminal hairballs, and abomasal lesion prevalence, lesion number, and lesion size comparable with those in milk-fed calves (except for scars). Calves were, thus, able to select an amount of $\mathrm{HY}$ that resulted in improvements in behavior and gastrointestinal health when compared with all other treatments. The amount of HY that ad libitum-fed calves chose in this study may give an indication of how much roughage veal calves should actually be fed in practice when welfare is to be maximized, although different sources of roughage or a combination of different roughages might lead to differences in voluntary intake. It may be useful to give calves free choice of a variety of roughages, and potentially concentrates, to evaluate what, and how much, solid feed calves would choose to consume on top of MR.

\section{CONCLUSIONS}

The present study suggests that the EU 1997 Directive on veal calf minimum solid feed requirements needs further specification as to source(s) and particle size of roughage to be fed, and an increase in the minimum amount stated, if the welfare of veal calves is to be improved. Different sources of roughage, and even different roughage particle sizes, affected the welfare of veal calves, in terms of both behavior and gastrointestinal health, differently. In particular, STR improved behavior and reduced ruminal hairball prevalence, but increased abomasal damage. More roughage (i.e., $500 \mathrm{~g}$ instead of $250 \mathrm{~g}$ of $\mathrm{DM} / \mathrm{d}$ ) increased chewing and rumination and reduced abnormal oral behaviors. Although this study did not investigate feeding a combination of different roughage sources, none of the single sources used in the present study improved both behavior and gastrointestinal health. A combination of different roughage sources may be necessary to improve both behavior and health, including those that facilitate good rumen development (e.g., maize silage), encourage chewing and rumination, and effectively eliminate ingested hair (e.g., STR).

\section{ACKNOWLEDGMENTS}

This study was funded by the European Commission, Directorate General for Agriculture, within the framework of the RTD contract FAIR 2049: "Chain Management of Veal Calf Welfare." The content of this publication is the sole responsibility of its publishers and does not represent the views of the Commission or it services. The Dutch Ministry of Agriculture, Nature Management and Fisheries (Den Haag, the Netherlands) also supported the study. The authors thank Denkavit Nederland B.V. (Voorthuizen, the Netherlands) and the VanDrie Group (Mijdrecht, the Netherlands) for practical support and advice, Ad van Vuuren (Livestock Research, Wageningen University and Research Centre, Lelystad, the Netherlands) for valuable input on calf nutrition during the design of the experiment, and Ad Korevaar (Central Veterinary Institute, Wageningen University and Research Centre) for expertly carrying out the pathological examinations. Finally, we thank Daniela de Araújo Angeja (Livestock Research, Wageningen University and Research Centre) for significant help with the data collection, and Dennis Webb (Cell Physiology, University of Rennes, France) for language editing.

\section{REFERENCES}

Beharka, A. A., T. G. Nagaraja, J. L. Morrill, G. A. Kennedy, and R. D. Klemm. 1998. Effects of form of the diet on anatomical, microbial, and fermentative development of the rumen of neonatal calves. J. Dairy Sci. 81:1946-1955.

Berends, H., C. G. van Reenen, N. Stockhofe-Zurwieden, and W. J. J. Gerrits. 2012. Effects of early rumen development and solid feed composition on growth performance and abomasal health in veal calves. J. Dairy Sci. 95:3190-3199.

Breslow, N. E., and D. G. Clayton. 1993. Approximate inference in generalized linear mixed models. J. Am. Stat. Assoc. 88:9-25.

Breukink, H. J., T. Wensing, and J. M. V. M. Mouwen. 1991. Abomasal ulcers in veal calves: Pathogenesis and prevention. Pages 118122 in New Trends in Veal Calf Production. J. H. M. Metz and C. M. Groenestein, ed. European Federation of Animal Science (EAAP) Publication no. 52. Pudoc, Wageningen, the Netherlands.

Broom, D. M., and A. F. Fraser. 2007. Domestic Animal Behaviour and Welfare. 4th ed. CAB International, UK.

Brscic, M., L. F. M. Heutinck, M. Wolthuis-Fillerup, N. Stockhofe, B Engel, E. K. Visser, F. Gottardo, E. A. M. Bokkers, B. J. Lensink, G. Cozzi, and C. G. Van Reenen. 2011. Prevalence of gastrointestinal disorders recorded at postmortem inspection in white veal calves and associated risk factors. J. Dairy Sci. 94:853-863.

Cozzi, G., F. Gottardo, F. Mutinelli, B. Contiero, G. Fregolent, S. Segato, and I. Andrighetto. 2002. Growth performance, behaviour, 
forestomach development and meat quality of veal calves provided with barley grain or ground wheat straw for welfare purpose. Ital. J. Anim. Sci. 1:113-126.

de Wilt, J. G. 1985. Behaviour and welfare of veal calves in relation to husbandry systems. PhD Thesis. Wageningen University, Wageningen, the Netherlands.

EC (European Council). 1997. Directive 97/2/EC. Page 25/24 in Official Journal of the European Communities. Vol. 20. EC, Brussels, Belgium.

Felt, B. T., and B. Lozoff. 1996. Brain iron and behavior of rats are not normalized by treatment of iron deficiency anemia during early development. J. Nutr. 126:693-701.

Flatt, W. P., R. G. Warner, and J. K. Loosli. 1958. Influence of purified materials on the development of the ruminant stomach. J. Dairy Sci. 41:1593-1600.

Greenwood, R. H., J. L. Morrill, E. C. Titgemeyer, and G. A. Kennedy. 1997. A new method a measuring diet abrasion and its effect on the development of the forestomach. J. Dairy Sci. 80:2534-2541.

Harrison, H. N., R. G. Warner, E. G. Sander, and J. K. Loosli. 1960. Changes in the tissue and volume of the stomachs of calves following the removal of dry feed or consumption of inert bulk. J. Dairy Sci. 43:1301-1312.

Haskins, B. R., M. B. Wise, H. B. Craig, T. N. Blumer, and E. R. Barrick. 1969. Effects of adding low levels of roughages or roughage substitutes to high energy rations for fattening steers. J. Anim. Sci. 29:345-353.

Heinrichs, J. 2005. Rumen Development in the Dairy Calf. Vol. 17. Advances in Dairy Technology. University Alberta Dept. Agric., Food \& Nutr Sci., Edmonton, AB, Canada.

Jelinski, M. D., C. S. Ribble, J. R. Campbell, and E. D. Janzen. 1996. Descriptive epidemiology of fatal abomasal ulcers in Canadian beef calves. Prev. Vet. Med. 26:9-15.

Katchuik, R. 1992. Abomasal disease in young beef calves: Surgical findings and management factors. Can. Vet. J. 33:459-461.

Lozoff, B., and G. M. Brittenham. 1986. Behavioral aspects of iron deficiency. Prog. Hematol. 14:23-53.

Martin, P., and P. Bateson. 2001. Measuring Behaviour. An Introductory Guide. Cambridge University Press, UK.

Mattiello, S., E. Canali, V. Ferrante, M. Caniatti, F. Gottardo, G. Cozzi, I. Andrighetto, and M. Verga. 2002. The provision of solid feeds to veal calves: II. Behavior, physiology, and abomasal damage. J. Anim. Sci. 80:367-375.

McCullagh, P., and J. A. Nelder. 1989. Generalized Linear Models. Chapman and Hall, London, UK.

McCulloch, C. E., S. R. Searle, and J. M. Neuhaus. 2008. Generalized, Linear, and Mixed Models. 2nd ed. John Wiley \& Sons Inc., Hoboken, NJ.

Morisse, J. P., J. P. Cotte, D. Huonnic, and A. Martrenchar. 1999. Influence of dry feed supplements on different parameters of welfare in veal calves. Anim. Welf. 8:43-52.

Suárez, B. J., C. G. Van Reenen, N. Stockhofe, J. Dijkstra, and W. J. J. Gerrits. 2007. Effect of roughage source and roughage to concentrate ratio on animal performance and rumen development in veal calves. J. Dairy Sci. 90:2390-2403.

Tamate, H., A. D. McGilliard, N. L. Jacobson, and R. Getty. 1962. Effect of various dietaries on the anatomical development of the stomach in the calf. J. Dairy Sci. 45:408-420.

Tamminga, S., W. M. Van Straalen, A. P. J. Subnel, R. G. M. Meijer, A. Steg, C. J. G. Wever, and M. C. Blok. 1994. The Dutch protein evaluation system: The DVE/OEB-system. Livest. Prod. Sci. 40:139-155.

Tulleners, E. P., and G. F. Hamilton. 1980. Surgical resection of perforated abomasal ulcers in calves. Can. Vet. J. 21:262-264.

Van Es, A. J. H. 1978. Feed evaluation for ruminants. I. The systems in use from May 1977 onwards in the Netherlands. Livest. Prod. Sci. 5:331-345.

Veissier, I., A. R. Ramirez de la Fe, and P. Pradel. 1998. Nonnutritive oral activities and stress responses of veal calves in relation to feeding and housing conditions. Appl. Anim. Behav. Sci. 57:35-49.

VSN International Ltd. 2012. GenStat for Windows. 15th ed. VSN International Ltd., Hemel Hempstead, UK.

Webb, L. E., E. A. M. Bokkers, B. Engel, H. Berends, W. J. J. Gerrits, and C. G. van Reenen. 2012. Behaviour and welfare of veal calves fed different amounts of solid feed supplemented to a milk replacer ration adjusted for similar growth. Appl. Anim. Behav. Sci. 136:108-116.

Wiepkema, P. R., K. K. Van Hellemond, P. Roessingh, and H. Romberg. 1987. Behaviour and abomasal damage in individual veal calves. Appl. Anim. Behav. Sci. 18:257-268. 